\title{
PLANTAS PARÁSITAS DEL SUR DEL PERÚ ESTUDIO BIOSISTEMÁTICO
}

Rosario Zegarra ${ }^{1}$

\section{R E S U M E N}

\begin{abstract}
Existen especies vegetales dentro de las Fanerógamas cuya nutrición es heterótrofa, a diferencia de la mayoría que son aulótrofas. Esto se debe a la alrofia de alguno de sus órganos necesarios, convirtiéndose en parásitas. En el Perí existen mas de 100 especies parásilas. Para el departamento de. Tacna se describen tres.
\end{abstract}

\section{INTRODUCCIÓN}

Una parte de las especies vegetales (parásitos) se han especializado en vivir a expensas de otros vegetales (hospedantes) obteniendo el alimento mediante HAUSTORIOS (órganos suctores particulares) los cuales se ponen en contacto anatómico con el sistema conductor del hospedante.

Las especies parásitas a las que nos estamos refiriendo se clasifican en:

A. Hemiparásitas: con parasitismo parcial. Se limitan a conectar su sistema de conducción de agua (xilema) con el de la planta hospedante. Son capaces de realizar la función fotosintética, al disponer de clorofila. Ejemplo: especies de la familia de las Loranthaceas.

B. Holoparásitas: con parasitismo estricto. Desprovistas de clorofila. Presentan a menudo una gran reducción de los órganos vegetativos. Las hojas innecesarias se reducen a escamas poco aparentes o no existen. El tallo sin color verde o un verde pálido. Mediante los Haustorios llegan a los vasos leñosos y tubos cribosos (floema) extrayendo savia inorgánica y orgánica respectivamente. Ejemplo: especies de las familias de las Cuscutáceas y Orobancáceas.

Las plantas parásitas en el paso del tiempo siempre han concitado la atención de propios y extraños, alrededor de ellas se han tejido numerosas leyendas.

1. Bióloga.

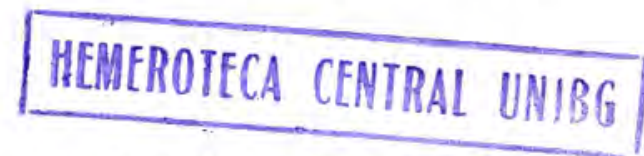

La mención que se hace en el Antiguo Testamento con referencia al "arbusto ardiente" es porque un árbol parasitado por el "muérdago", da la apariencia de estar en llamas por la coloración amarillo dorado de sus flores.

En la obra La Eneida del poeta Virgilio se hace alusión al muérdago como el "arbusto de oro".

William Shakespeare en referencia al "muérdago" lo denomina como "ominoso muérdago".

En los países europeos se ha considerado al "muérdago", como planta símbolo de paz, amistad, fertilidad. En el Perú las especies parásitas son conocidas desde el imperio incaico.

Actualmente los nombres comunes más conocidos son "Liga" (Psittacanthus), "Cabellos de ángel" (Cuscuta), "Ladrón de árboles" (Phoradendron), "Mata Palo" (Gaiadendron), "Destructor de árboles" (Dendrophthora).

Las familias de Fanerógamas parásitas representativas para el Perú son:

a) Lorantháceas: con 8 géneros: Gaiadendron, Phrygilantus, Psittacanthus, Struthanthus, Dendrophthora, Setanthus, Phoradendron, Oryctanthus.

b) Santaláceas: presenta 3 géneros : Arjona, Cervantesia y Quinchamalium.

c) Cuscutáceas: con un género Cuscuta.

d) Orobancáceas: un solo género Orobanche.

e) Balanophoraceas: con el género Helosis. 


\section{TRATAMIENTO SISTEMÁTICO DE LAS ESPECIES DEL DEPARTAMENTO DE TACNA}

\section{A. FAMILIA LORANTHACEAE}

Psittacanthus cuneifolius (R\&P.) G. Don "Liga, pupa, suelda con suelda, liguilla"

Especie arbustiva glabra, desprovista de raíz, ramas erguidas robustas.

Hojas simples, opuestas sésiles, suculentas, oblongo espatuladas o cuneiformes, lustrosas verde oscuro. Flores hermafroditas actinomorfas solitarias axilares, pediceladas. Cáliz pequeño gamosépalo sinuado denticulado. Corola tubulosa con seis pétalos rojizos. Androceo con seis estambres, opuestos a los sépalos con las anteras amarillas.

Gineceo con el estigma pequeño, estilo filiforme, ovario ínfero con placentación central. Polinización ornitófila.

Fruto : esférico de color negro, con una semilla envuelta por una sustancia pegajosa y viscosa, rodeado por el cáliz tubuloso.

Propagación : por las semillas, las aves diseminan éstas al ingerir los frutos mediante sus deyecciones.

Germinación : si las semillas están húmedas, éstas germinan, y se fijan en la planta hospedante mediante un haustorio que se ramifica radialmente

FIGURA N 01:Psittacanthus cuneifolius, especie semiparásita común de las zonas altoandinas de Tacna (Tarata y Ticaco) parasitando una rama de peral. Esta especie tiene una inflorescencia muy vistosa y ornamental.

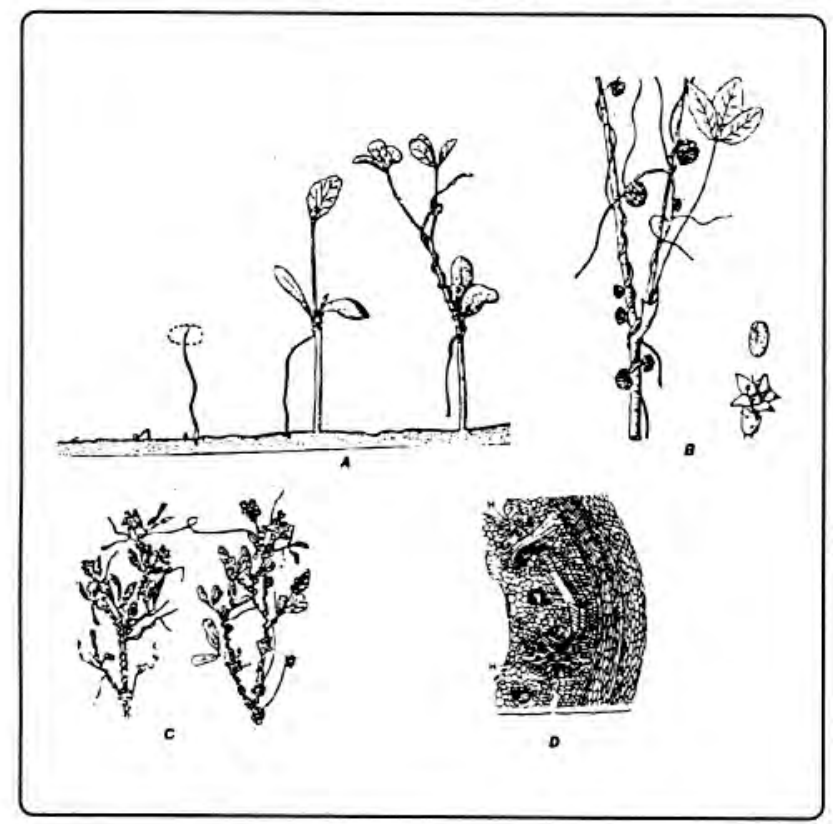

desde el punto de ingreso en la corteza, introduciéndose en la rama llegando al xilema hasta obtener la savia inorgánica.

Plantas hospedantes: especies frutales de la familia de las Rosáceas, por ejemplo: peral, ciruelo, duraznero, manzano, membrillero $u$ otras plantas como el molle, rocke.

Daños : cuando la infestación es intensa abarcando un gran número de árboles frutales constituye un peligro.

Aplicaciones : el jugo viscoso se emplea como liga para cazar aves y para confeccionar parches empleados para fracturas (fig. 01).

\section{B. FAMILIA CUSCUTACEAE}

\section{Cúscuta grandiflora HBK "Cabellos de Ángel"}

Especie voluble, sin raices, tallo filiforme voluble delgado de color amarillento o rojizo; hojas escuamiformes, flores agrupadas en glomérulos densos en número de diez a veinte. Flores hermafroditas, actinomorfas. Cáliz pentámero acampanado. Corola urceolada con cinco pétalos. Androceo con cinco estambres epipétalos. Ovario súpero bicarperlar. Polinizacion autógama.

Fruto : capsular globoso de color café con cuatro semillas rugosas.

Propagación : por las semillas.

Germinación : Ias semillas de Cuscuta al encontrar condiciones extrínsecas favorables germinan. En el estado de plántula presenta una raíz temporal y emite un tallo pequeño filamentoso amarillo, el cual gira mediante movimientos de nutación (oscilatorios circulares en el aire) en torno de la planta hospedante. El tallo de Cuscuta presenta cuatro capas corticales. Se desarrolla un cojinete aplastado a partir de las dos capas más externas, este cojinete se une firmemente a la epidermis de la planta hospedante, en el centro de el implicando a las cuatro capas corticales, crece un órgano penetrante: el haustorio. La punta del haustorio penetra entre las células epidérmicas en la corteza de la planta hospedante, esta punta está constituida por hifas. En la corteza las hifas crecen independientemente, se dispersan por los tejidos conectándose con los elementos del tejido conductor. Se diferencia el Xilema y el Floema en el haustorio y se forma una conexión entre los tejidos vasculares de Cuscuta y la planta hospedante.

Posteriormente buscan más plantas 
FIGURA N $N^{\circ}$ 02: Cuscuta grandiflora, especie parásita común en la costa y sierra del sur del Perú, donde mayormente parasita plantas de alfalfa. A: Germinación e inicio de parasitismo en el hospedante. B: Glomérulos de flores de Cuscuta, semilla y flor. C: Planta de Alfalfa parasitada. D: Corte anatómico de los haustorios de Cuscuta y el tallo de alfalfa.

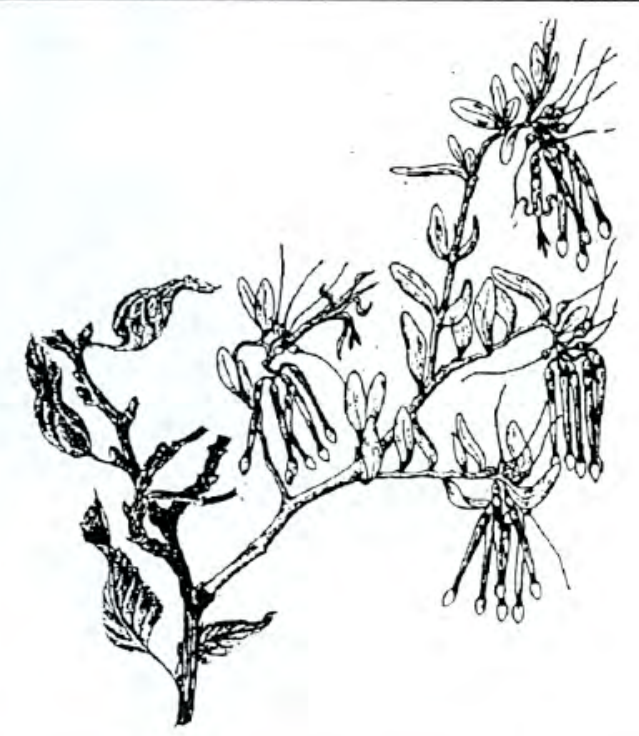

hospedantes, la Cuscuta florece, fructifica, cayendo las semillas al suelo o son llevadas por el agua de riego.

Plantas hospedantes : alfalfa, trébol, tiquil-tiquil.

Daños : al invadir un cultivo de alfalfa, causa daños económicos al debilitarlas general o parcialmente, al succionarles la savia inorgánica y elaborada (fig.2).

\section{FAMILIA ORABANCACEAE}

\section{Orobanche tacnaensis Mattf "Orobanca"}

Especie parásita de $15-45 \mathrm{~cm}$. Tallo aéreo florifero grueso, carnoso, arranca del interior de un tubérculo hipocotileo que esta intimamente unido mediante un haustorio subterráneo con una raíz de la planta hospedante. La coloración del tallo es amarillento, marrón, púrpura, rosado. Hojas reducidas a escamas.

Flores agrupadas en espigas en la axila de una bráctea. Hermafroditas y zigomorfas, entomógamas. Cáliz con 2 sépalos. Corola tubulosa de variados colores bilabiada con 5 pétalos. Androceo con 4 estambres epitétalos didinamos. Ovario supero bicarpelar unilocular con placentacion parietal.

Fruto: capsular con numerosas semillas diminutas Propagación : por semillas.

Germinación : las semillas sólo germinan cuando se ponen en contacto con las raices de la planta hospedante o nodriza, únicamente sobresale del subsuelo los tallos florales, al costado de la planta hospedante.

Plantas hospedantes : chiñe, marco, chillca.

Daños : hospedantes débiles o cloróticos. Las especies del género Orobanche tienen sus plantas hospedantes preferidas, cuando estas son leguminosas como habas, arvejas u otras, causan daños de consideración al destruirse parcial o totalmente las cosechas (fig.3).

FIGURA N $N^{\circ}$ 02: Orobanche tacnesis, planta parásita de arbustos en el valle de Tacna. A: Germinación de la semilla sobre la raiz parasitada. B: Planta adulta floreciendo y parasitando la raiz de otra planta. C: Flores tubulares de Orobanche.

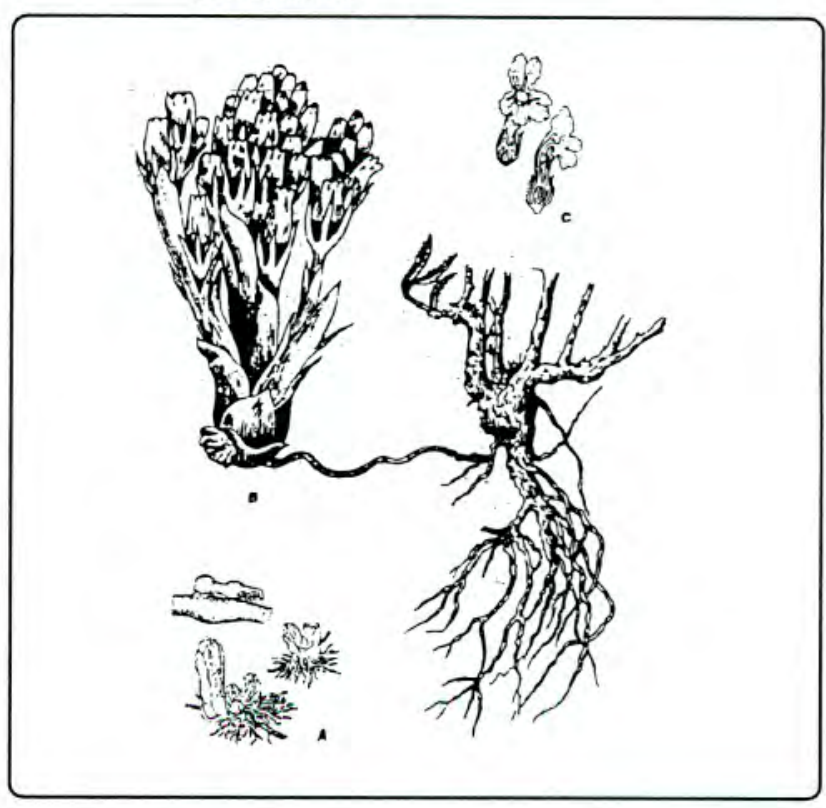

\section{REFERENCIAS BIBLIOGRÁFICAS}

JEAN-PROST P. (1970). La Botánica y sus aplicaciones agricolas. Ediciones Memdi-Prensa. Madrid, España.

STRASBURGER E. Y OTROS (1985). Tratado de Botánica. Editorial Marín. Barcelona, España.
ZEGARRA R. (1994). La vegetación desértica perenne de Tacna: Estudio Biosistematico y sus recursos naturales. Revistas Nueva Imagen $N^{\circ} 5$ UNJBG. Tacna, Perú. 